\title{
Effect of Supervised Home-Based Training on Functional Outcome in Severe Exercise Intolerance in Post-COVID Syndrome
}

\author{
Shraddha Shah \\ Department of Physiotherapy, Manipal College of Health Professions, Manipal, Karnataka, India
}

\section{Abstract}

Globally, millions of people have been impacted with COVID-19. A fraction of these people develop severe respiratory distress and require prolonged intensive care unit stay. With this, and with the improving recovery rate, the numbers of post-COVID survivors are steeply increasing. This demands an early, effective, inexpensive, and safe post-COVID pulmonary rehabilitation (PR) in a low available resource setting. A 56-year-old female diagnosed to have COVID-19 pneumonitis with acute respiratory distress syndrome developed severe exercise limitation after discharge, and a supervised low resource home-based PR program was initiated. The PR was followed as per the American Thoracic society/European Respiratory Society guidelines for 6 weeks with supplemental oxygen with a progressive metabolic equivalent of task level training. By the end of 6 weeks, the patient was independent in most of her self-care activities and was ambulatory in and around the house. We conclude with this case report that, by maintaining necessary precautions as recommended by the World Health Organization, PR can be delivered to remotest places with minimal resources and the outcome of this can make an individual independent in the self-care activities at the least.

Keywords: COVID-19, critical illness, exercise intolerance, low-resource, pulmonary rehabilitation

\section{INTRODUCTION}

The World Health Organization (WHO) announced a global outbreak of COVID-19 disease, a pandemic on March 11, 2020. On March 24, 2020, India announced a nationwide lockdown to curb the spread of infection. With a steep increase in the number of cases, India presently has the second-highest number of cases globally. ${ }^{[1]}$ However, from the recent data (as on October 24, 2020), the recovery rate was documented to be $90 \%$ and mortality rate plummeted to $1.51 \%$. ${ }^{[2]}$ With an increase in the number of post-COVID survivors, there is a need for prompt pulmonary rehabilitation (PR) to improve and maintain lung function and quality of life.

The pioneers in PR and the respiratory societies have worked tirelessly to come up with updates in guidelines. ${ }^{[3,4]}$ These studies, in a nutshell, testify the role of acute rehabilitation in COVID-19 patients. However, the role of PR in post-COVID survivors is uncertain. This case report throws light on optimal exercise-based PR in these patients.

\begin{tabular}{|l|l|}
\hline \multicolumn{3}{|c|}{ Access this article online } \\
\hline Quick Response Code: & Website: \\
\hline & www.ijrc.in \\
\hline
\end{tabular}

\section{Case Report}

A 56-year-old, nil premorbid female, diagnosed to have asymptomatic COVID-19 by contact tracing was advised home isolation. Two days later, she developed respiratory distress and was admitted to the intensive care unit (ICU) after being diagnosed to have viral pneumonitis with acute respiratory distress syndrome (ARDS). Investigations revealed C-reactive protein of $119.91 \mathrm{mg} / \mathrm{L}$, lactate of $738 \mathrm{U} / \mathrm{L}$, and D-dimer of $589.27 \mathrm{ng} / \mathrm{mL}$. An arterial blood gas done on a nonrebreather mask (NRBM) revealed $\mathrm{pH}$ of 7.392, $\mathrm{PaO}_{2}$ of $83 \mathrm{mmHg}, \mathrm{PaCO}_{2}$ of $40 \mathrm{mmHg}$, and $\mathrm{HCO}_{3}$ of $24.4 \mathrm{mmol} / \mathrm{L}$.

Address for correspondence: Ms. Shraddha Shah, Department of Physiotherapy, Manipal College of Health Professions, Manipal - 576 104, Karnataka, India. E-mail: shah.shraddha514@gmail.com

This is an open access journal, and articles are distributed under the terms of the Creative Commons Attribution-NonCommercial-ShareAlike 4.0 License, which allows others to remix, tweak, and build upon the work non-commercially, as long as appropriate credit is given and the new creations are licensed under the identical terms.

For reprints contact:WKHLRPMedknow_reprints@wolterskluwer.com

How to cite this article: Shah S. Effect of supervised home-based training on functional outcome in severe exercise intolerance in post-COVID syndrome. Indian J Respir Care 2021;10:240-2.

Received: 03-12-2020

Revised: $17-03-2021$

Accepted: 05-04-2021 
Shah: Supervised home-based training and post-COVID functional outcome

High-resolution computed tomography (HRCT) showed ground-glass opacities in both upper lobes, right middle lobe, and both lower lobes. Computed tomography (CT) scan and CT severity index of 24/25 indicated typical CoV-19 presentation. Her condition deteriorated with increasing D-dimer, lactate, and hypoxemia with severe respiratory acidosis, and this was managed with noninvasive ventilation, injectable tocilizumab, and other symptomatic management. Active assisted bed mobility exercises were initiated after 20 days of admission. She was discharged from hospital after 40 days with continuous supplemental oxygen administration through nasal cannula (NC).

Post-COVID rehabilitation began a month after discharge. She was well oriented to time, place, and person. In supine position, her heart rate (HR) was $112 / \mathrm{min}$, respiratory rate (RR) $16 / \mathrm{min}$, blood pressure $110 / 78 \mathrm{mmHg}$, and $\mathrm{SpO}_{2} 98 \%$ at $4 \mathrm{~L} / \mathrm{min}_{2}$ on NC. On day 1, with supportive transition from supine to sitting, she became tachypneic $(R R=24 / \mathrm{min})$ and breathless with the increased use of accessory respiratory muscles, increased RR, and supraclavicular retractions. She was incapable of speaking in complete sentences.

Further examination revealed a shallow pattern of breathing, and on auscultation, late inspiratory crackles were heard in the bilateral upper posterior and lower posterior lung fields. Foley's catheter was in situ as she was nonambulatory. Medical Research Council-Sum Score (MRC-SS) was used to assess ICU-acquired weakness (MRC-SS $=46 / 60$ ). Proximal muscles were found to be weaker than the distal muscles. The independence in activities of daily livings (ADLs) was measured using the functional independent measure (FIM) scale, where she scored 77/126. At $10 \mathrm{~m}$ of supported walking, she was breathless and her $\mathrm{SpO}_{2}$ dropped to $48 \%-50 \%$. She was instantly placed on NRBM at $10 \mathrm{~L} / \mathrm{min}_{2}$.

The PR began the next day with the following short-term goals: (1) to reduce dyspnea, (2) to enhance lung expansion, and (3) to ambulate independently (almost $20 \mathrm{~m}$ ), enough to remove the urinary catheter. The protocol was designed as per the standard PR guidelines. ${ }^{[5]}$

As the patient had severe exercise intolerance, all the exercises were performed with an increase in supplemental oxygen [Figure 1]. For the initial 2 weeks, functional training included symptom-limited walking $(10-15 \mathrm{~m})$ where the patient's HR increased 25-30 beats from baseline and her rating of perceived exertion was $13-14$ on a 6-20 Borg's scale. Strength training began with a $0.5 \mathrm{~kg}$ weight cuff. Flexibility training included stretching larger muscles of the upper and lower limb. She equally performed diaphragmatic breathing and lung expansion exercises twice per session. A comprehensive description of the exercise testing and prescription is presented in Table 1. Moreover, nutritional counseling was done once a week, and education sessions on the disease process, oxygen therapy, role of exercise, and irritant avoidance were delivered at frequent intervals.

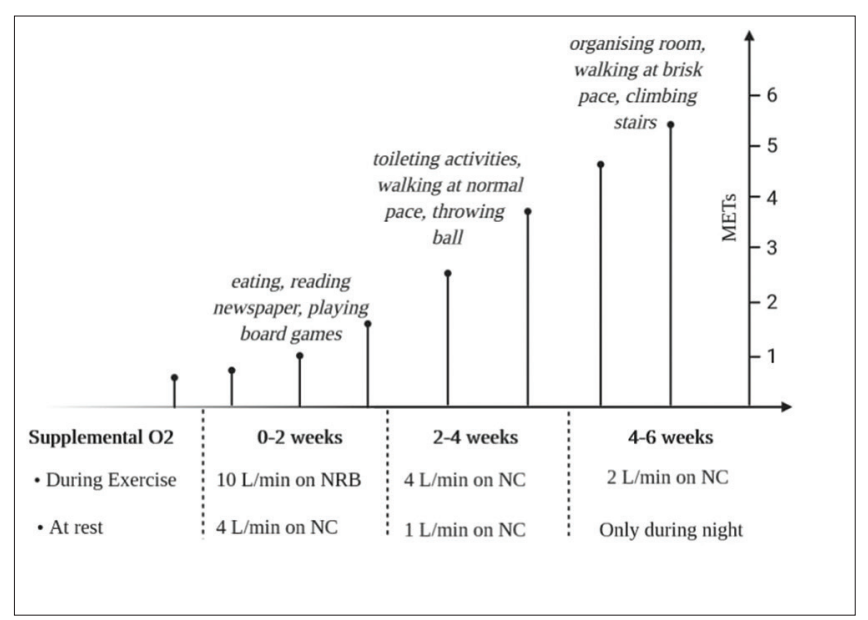

Figure 1: Timeline of training with few progressive metabolic equivalent of task level activities and subsequent weaning demands of supplemental oxygen

In addition, with a $15 \mathrm{~m}$ tube attached to the $\mathrm{O}_{2}$ source, she could walk 25-30 m maintaining her $\mathrm{SpO}_{2}$. From the $3^{\text {rd }}$ week, we began with squatting exercises. After the $4^{\text {th }}$ week, Foley's catheter was removed, and she was capable of walking 50-60 m independently. By end of 6 weeks, her FIM score was 110/126, with her being independent with most of her activities and her 6-min walk distance (6MWD) was $250 \mathrm{~m}$ [Table 1].

Furthermore, this case progressed in a novel way following the metabolic equivalent of task (MET) level activities [Figure 1]. Multiple activities with progressive METs were practiced for 40-60 min daily, beginning with light 1.5-2 METs to 4-5 METs of activities by 6 weeks, with progressively weaning oxygen. There were no episodes of any adverse events. After 6 weeks, the supervised sessions were tapered down, and a home-based rehabilitation protocol was prescribed.

\section{Discussion}

While the long-term sequel of COVID-19 remains to be understood, we know ARDS and prolonged bed rest impair the physical condition of the body. ${ }^{[6]}$ To the best of our knowledge, this was the first case study from a low resource setting reporting the functional outcomes following PR in post-COVID survivors.

PR is a multidisciplinary approach to improve physical and psychological functioning in chronic respiratory diseases. ${ }^{[5]}$ However, a multidisciplinary PR program requires an expansive setup and experienced staff. Therefore, their results cannot be reflected in low-resource setups. This case report represents rehabilitation in a low resource setting. The advantage of this supervised home-based rehabilitation was that the patient did not have to travel with the oxygen unit for rehabilitation.

A systematic review revealed a significant improvement in 6MWD and dyspnea with PR in patients with pulmonary fibrosis. ${ }^{[7]}$ We assume that, since the pulmonary fibrosis as observed here is irreversible, the probable mechanism of 
Shah: Supervised home-based training and post-COVID functional outcome

\begin{tabular}{|c|c|c|c|c|}
\hline & $0-2$ weeks & 2-4 weeks & 4-6 weeks & Post 6 weeks \\
\hline \multicolumn{5}{|l|}{ Functional testing } \\
\hline Test & $\begin{array}{l}\text { Symptom limited walk } \\
\text { test off supplemental } \mathrm{O}_{2}\end{array}$ & $\begin{array}{l}1 \text { min STS test on } \\
\text { supplemental } \mathrm{O}_{2}\end{array}$ & $\begin{array}{l}1 \text { min STS test on } \\
\text { supplemental } \mathrm{O}_{2}\end{array}$ & $6 \mathrm{MWT}$ off supplemental $\mathrm{O}_{2}$ \\
\hline Outcome & $10 \mathrm{~m}$ (breathless) & $\begin{array}{l}9 \text { repetitions in } \\
44 \mathrm{~s}\end{array}$ & 15 repetitions in $1 \mathrm{~min}$ & $250 \mathrm{~m}$ with a break \\
\hline Functional training & $\begin{array}{l}\text { Symptom limited } \\
\text { walking } \times 2 \text { day }\end{array}$ & $\begin{array}{l}\text { Walking + } 6 \\
\text { repetitions-STS/ } \\
\text { min }\end{array}$ & $\begin{array}{l}\text { Walking }+10 \\
\text { repetitions-STS/min }\end{array}$ & $\begin{array}{l}\text { Walking } 550 \mathrm{~m} \\
(3 \text { bouts } \times 180 \mathrm{~m} \text { in } 5 \mathrm{~min})\end{array}$ \\
\hline Strength training (set $/ \mathrm{s} \times$ repetitions) & $1 \times 10(0.5 \mathrm{~kg} / \mathrm{LL})$ & $\begin{array}{l}2 \times 10(0.5 \mathrm{~kg} / \mathrm{UL} \\
\text { and } 1 \mathrm{~kg}-\mathrm{LL})\end{array}$ & $2 \times 12(1 \mathrm{~kg} / \mathrm{UL}$ and LL $)$ & $2 \times 15(1 \mathrm{~kg} / \mathrm{UL}$ and LL $)$ \\
\hline Flexibility training (set $/ \mathrm{s} \times$ repetitions) & $1 \times 3$ & $1 \times 3$ & $1 \times 3$ & $1 \times 3$ \\
\hline Breathing exercises & \multicolumn{4}{|c|}{ Diaphragmatic breathing + thoracic expansion exercises } \\
\hline
\end{tabular}

STS: Sit to stand, 6MWT: 6 min walk test

improvement in the exercise capacity could be attributed to enhanced oxygen extraction and consumption by peripheral skeletal muscles as observed in patients with pulmonary hypertension. ${ }^{[8,9]}$ Moreover, the progressive MET level of training could have led to the adaptation of the cardiopulmonary system. Thus, with a supervised home-based rehabilitation following WHO guidelines, the penetration of the PR can be enhanced to reach the peripherals of the community safely.

\section{ConcLusion}

Despite the rehabilitation being delayed and with low available resources, a patient with post-COVID severe functional limitation can be managed with effective PR. The patient can be trained to conduct her ADLs independently by progressive PR and metabolic equivalent (MET) level training. Further research is required at the community level to study the effect of PR on the long-term consequences of this disease.

\section{Declaration of patient consent}

The authors certify that they have obtained all appropriate patient consent forms. In the form the patient(s) has/have given his/her/their consent for his/her/their images and other clinical information to be reported in the journal. The patients understand that their names and initials will not be published and due efforts will be made to conceal their identity, but anonymity cannot be guaranteed.

\section{Financial support and sponsorship} Nil.

\section{Conflicts of interest}

There are no conflicts of interest.

\section{RefERENCES}

1. Available from: https://covid.who.int/. [Last accessed on 2020 Oct 25].

2. Availablefrom: https://www.mohwf.gov.in/. [Last accessed on 2020 Oct 25].

3. Spruit MA, Holland AE, Singh SJ, Tonia T, Wilson KC, Troosters T. COVID-19: Interim Guidance on Rehabilitation in the Hospital and Post-Hospital Phase from a European Respiratory Society and American Thoracic Society-coordinated International Task Force. Eur Respir J 2020;56:2002197.

4. Thomas P, Baldwin C, Bissett B, Boden I, Gosselink R, Granger CL, et al. Physiotherapy management for COVID-19 in the acute hospital setting: Clinical practice recommendations. J Physiother 2020;66:73-82.

5. Spruit MA, Singh SJ, Garvey C, ZuWallack R, Nici L, Rochester C, et al. An official American Thoracic Society/European Respiratory Society statement: Key concepts and advances in pulmonary rehabilitation. Am J Respir Crit Care Med 2013;188:e13-64.

6. Herridge MS, Tansey CM, Matté A, Tomlinson G, Diaz-Granados N, Cooper A, et al. Functional disability 5 years after acute respiratory distress syndrome. N Engl J Med 2011;364:1293-304.

7. Hanada M, Kasawara KT, Mathur S, Rozenberg D, Kozu R, Hassan SA, et al. Aerobic and breathing exercises improve dyspnea, exercise capacity and quality of life in idiopathic pulmonary fibrosis patients: Systematic review and meta-analysis. J Thorac Dis 2020;12:1041.

8. Babu AS, Padmakumar R, Nayak K, Shetty R, Mohapatra AK, Maiya AG. Effects of home-based exercise training on functional outcomes and quality of life in patients with pulmonary hypertension: A randomized clinical trial. Indian Heart J 2019;71:161-5.

9. Marra AM, Egenlauf B, Bossone E, Eichstaedt C, Grünig E, Ehlken N. Principles of rehabilitation and reactivation: Pulmonary hypertension. Respiration 2015;89:265-73. 